\title{
STATIC MODE STUDY OF THE IRRADIATION EFFECT ON \\ ELECTRICAL PARAMETERS OF A PARALLEL VERTICAL JUNCTION SILICON SOLAR CELL UNDER MONOCHROMATIC ILLUMINATION
}

\author{
Alioune Badara Dieng ${ }^{1}$, Fakoro Souleymane Dia ${ }^{2}$, Senghane Mbodj ${ }^{3}$, Ibrahima Ly ${ }^{4}$, \\ Gregoire Sissoko 5 \\ ${ }^{1}$ Faculty of Science and Technology, University Cheickh Anta Diop, Dakar, Senegal \\ ${ }^{2}$ Faculty of Science and Technology, University Cheickh Anta Diop, Dakar, Senegal \\ ${ }^{3}$ MPCI, University of Bambey, Bambey, Senegal \\ ${ }^{4}$ Electromecanic Department, Polytechnic Superior School, Thies, Senegal \\ ${ }^{5}$ Faculty of Science and Technology, University Cheickh Anta Diop, Dakar, Senegal
}

\begin{abstract}
In this article we have made a theoretical study of a parallel vertical junction solar cell under monochromatic illumination in static mode and under irradiation.

The resolution of the continuity equation which governs the electron scattering process in the base helps us to establish the expression of the electron density and deduce expressions of photocurrent density and photovoltage depending on the wavelength $\lambda$, recombination velocity at the junction and irradiation parameters.

Expressions series and shunt resistance according to the wavelength, the recombination velocity at the junction and irradiation parameters are obtained from the photovoltage and photocurrent density. We have studied the influence of irradiation variationon the electron density in the base, the photocurrent, photovoltage and the shunt and series resistances.
\end{abstract}

Keywords: - Silicon vertical junction- wavelength-shunt and series resistances-irradiation.

\section{INTRODUCTION}

We will make, through this article, a theoretical study of a parallel vertical junction solar cell under monochromatic illumination in static mode and under irradiation.

The resolution of the continuity equation helps us to establish the expression of the density of minority charge carriers in the base and deduct expressions of photocurrent density and photovoltage.

The series and shunt resistance were subsequently deducted. We will study, in this article, the impact of the change in coefficient of damage and the irradiation energy on the above listed parameters.

\section{THEORY}

We consider a solar cell type of parallel vertical junction $n^{+}$ -p-p whose structure may be represented as follows:

$* * *$

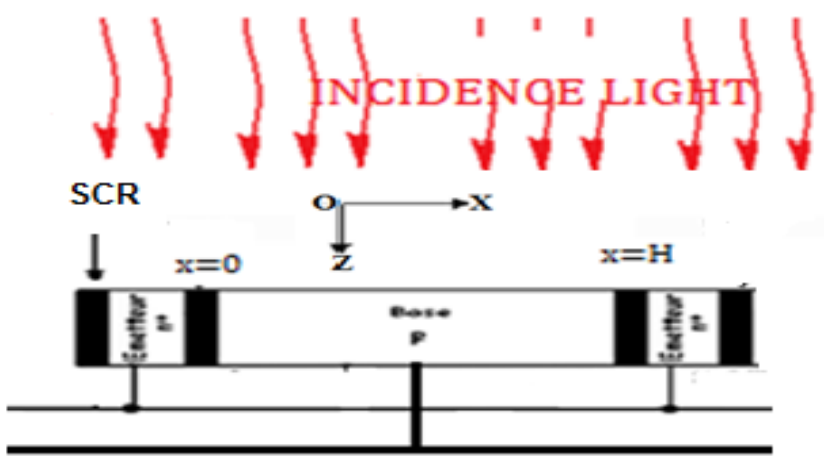

Fig 1: parallel vertical junctions of a solar cell

When the solar cell is illuminated, there are creation of electron-hole pairs in the base.

The behavior of the minority carriers in the base (electrons) is governed by the continuity equation including all the phenomena which cause the variation of the electrons density according to the width $\mathrm{x}$ of the base, its depth $\mathrm{z}$, the recombination velocity to the junction, of the wavelength and irradiation parameters. Solving this equation will enable 
us subsequently to have initially expressed the density of minority carriers from the base and deduct those quantities and other solar cells electrical parameters.

The continuity equation in static mode is presented under the form:

$$
D \cdot \frac{\partial^{2} \delta(x)}{\partial x^{2}}-\frac{\delta(x)}{\tau}=-G(z, \lambda)
$$

$\delta(x)$ describes the photogenerated minority charge carriers.

. $\mathrm{D}$ is the coefficient diffusion. $\tau$ is the average lifetime of carriers.

. $G(z, \lambda)$ is the overall generation rate of minority charge carriers according to the depth $\mathrm{z}$ of the base.

The continuity equation can still be written as follows:

$$
\frac{\partial^{2} \delta(x)}{\partial x^{2}}-\frac{\delta(x)}{L^{2}}+\frac{G(z)}{D}=0
$$

$$
L(k l, \phi)=\frac{1}{\sqrt{k l . \phi+\frac{1}{L_{o}^{2}}}} \text { is the diffusion length [1]. } \mathrm{L}_{\mathrm{O}} \text { is }
$$

the diffusion length with the absence of irradiation. $\mathrm{kl}$ and $\varphi$ denote the coefficient of damage and the irradiation energy. The expression of the overall generation of minority charge carriers rate is of the form: [2]

$$
G(z, \lambda)=\alpha(\lambda)(1-R(\lambda)) \cdot F \cdot \exp (-\alpha(\lambda) \cdot z)
$$

$R(\lambda)$ is the coefficient monochromatic reflection; $F$ is the incident photon flux from a monochromatic radiation. $\alpha$ is the coefficient of monochromatic absorption.

$$
\frac{\partial^{2} \delta(x)}{\partial x^{2}}-\frac{\delta(x)}{L^{2}}=-\frac{G(z)}{D}
$$

\subsection{Solution of the Equation of Continuity}

- Special solution:

$$
\delta_{1}(x)=\frac{L^{2}}{D} \alpha(\lambda)(1-R(\lambda)) \cdot F \cdot \exp (-\alpha(\lambda) \cdot z)
$$

-solution of the equation with second member:

$$
\delta_{2}(x)=A \cosh \left(\frac{x}{L}\right)+B \sinh \left(\frac{x}{L}\right)
$$

-as the general solution is:

$$
\delta(x, z, \lambda, S f, k l, \phi)=\left[\begin{array}{l}
A \cosh \left(\frac{x}{L(k l, \phi))}\right)+B \sinh \left(\frac{x}{L(k l, \phi)}\right) \\
+\frac{L^{2}(k l, \phi)}{D} \cdot \alpha(\lambda)(1-R(\lambda)) \cdot F \cdot \exp \left(-\alpha_{t} z\right)
\end{array}\right]
$$

\section{2- Search the Coefficients A and B}

- The boundary conditions:

-as at the junction $(x=0)$ we have:

$$
\left.D \cdot \frac{\partial \delta\left(x_{t}, z_{t}, \lambda, k l, \phi\right)}{\partial x}\right|_{x=0}=\left.S f \cdot \delta\left(x_{t}, z_{t}, \lambda_{t}, k l, \phi\right)\right|_{x=0}(\mathbf{8})
$$

$S f$ is the recombination velocity at the junction. This is a phenomenological parameter that describes how the base minority carriers go through the junction. It can be divided into two terms [3].

We have $S f=S f_{O}+S f_{j}$

$S f_{O}$ Induced by the shunt resistance, is the intrinsic recombination velocity. It depends only on the intrinsic parameters of the solar cell.

$S f_{j}$ reflects the current flow imposed by an external charge and sets the operating point of the solar cell

-At The middle of the base $\left(x=\frac{H}{2}\right)$.The structure of the solar cell, with two identical junctions on either side of the base, portends equation (9) below:

$$
\left.D \cdot \frac{\partial \delta(x)}{\partial x}\right|_{x=H / 2}=0
$$

$\mathrm{H}$ is the thickness of the solar cell's base

\section{Results and Discussion}

\subsection{Density Profile of Minority Carriers in the Base}

Figures 02-a and 02- b show the profile of the density of minority carriers in the base according to its width $\mathrm{x}$ there on respectively different values of the irradiation energy and the coefficient of damage. 


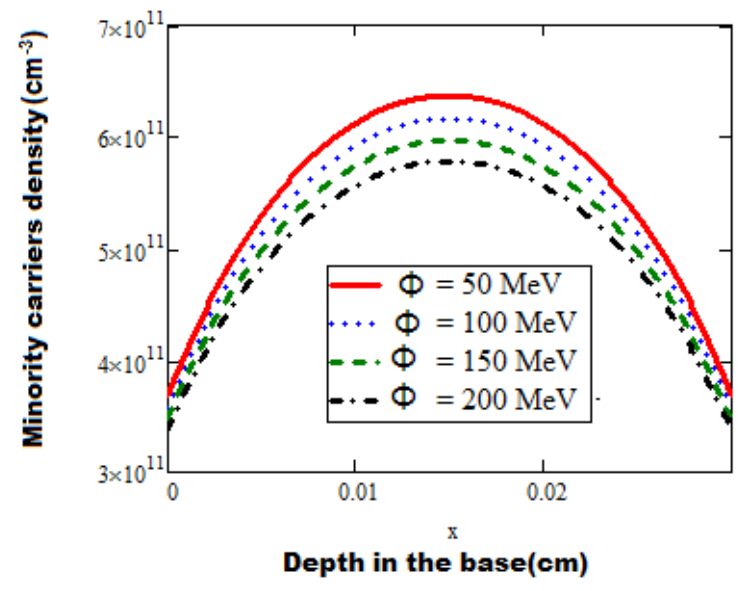

2-a) $\mathrm{kl}=10 \mathrm{~cm} / \mathrm{s}^{2}$

Fig 2-a: Variation of the density of minority carriers according to the thickness $\mathrm{x}$ of the base.

$\mathrm{Sf}=3.10^{3} \mathrm{~cm} / \mathrm{s} ; \lambda=0,7 \mu \mathrm{m} ; \mathrm{H}=0,03 \mathrm{~m} ; \mathrm{Z}=0,0001 \mathrm{~cm}$; $\mathrm{L}_{\mathrm{o}}=0,01 \mathrm{~cm}$

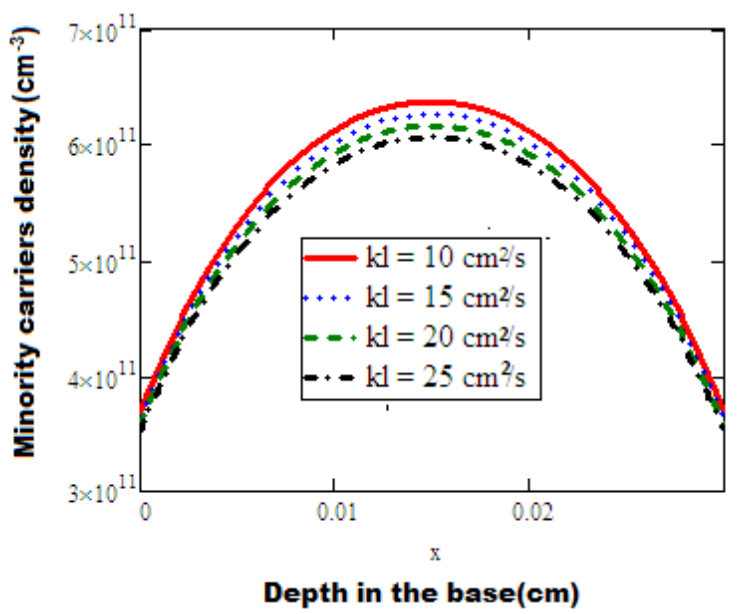

2-b) $\phi=50 \mathrm{Mev}$

Fig 2-b: Variation of the density of minority carriers according to the thickness $\mathrm{x}$ of the base.

$\mathrm{Sf}=3.10^{3} \mathrm{~cm} / \mathrm{s} ; \lambda=0,7 \mu \mathrm{m} ; \mathrm{H}=0,03 \mathrm{~m} ; \mathrm{Z}=0,0001 \mathrm{~cm}$; $\mathrm{L}_{\mathrm{o}}=0,01 \mathrm{~cm}$

The electron density is minimum at the junctions $(\mathrm{x}=0$ and $\mathrm{x}=\mathrm{H}$ ) and maximum in the middle of the base.

We also find that the density decreases when the coefficient of damage increases. The same report is done with the irradiation energy.

At the junctions, the recombination surface is very strong due in particular holes to the side of the space charge region located in the base and is powered by the internal electric field.

In the middle of the base density is highest because the phenomena of recombination are less developed here.
The irradiation causes the proliferation of recombination centers, which has the effect of reducing the density of minority carriers in the base.

\subsection{Photocurrent Density Profile}

The photocurrent of the solar cell obtained from the gradient of the minority carrier density is given by the expression (10):

$$
J_{P h}=\left.2 q \cdot D \cdot \frac{\partial \delta(x, z, S f, \lambda, k l, \phi)}{\partial x}\right|_{x=0}
$$

Where $\mathrm{q}$ is the elementary charge and $\mathrm{D}$ is the diffusion coefficient of electrons in the base. From where:

$$
J_{p h}=2 q \frac{S_{f} L^{3} \cdot \alpha_{t}(1-R) \cdot F \cdot \exp \left(-\alpha_{t} \cdot z\right) \cdot \tanh \left(\frac{H}{2 L}\right)}{S_{f} \cdot L+D \tanh \left(\frac{H}{2 L}\right)}
$$

Figures $03-\mathrm{a}$ and 03-b represent the profile of the photocurrent density according to the recombination velocity at the junction for respectively different values of the irradiation energy and the coefficient of damage.

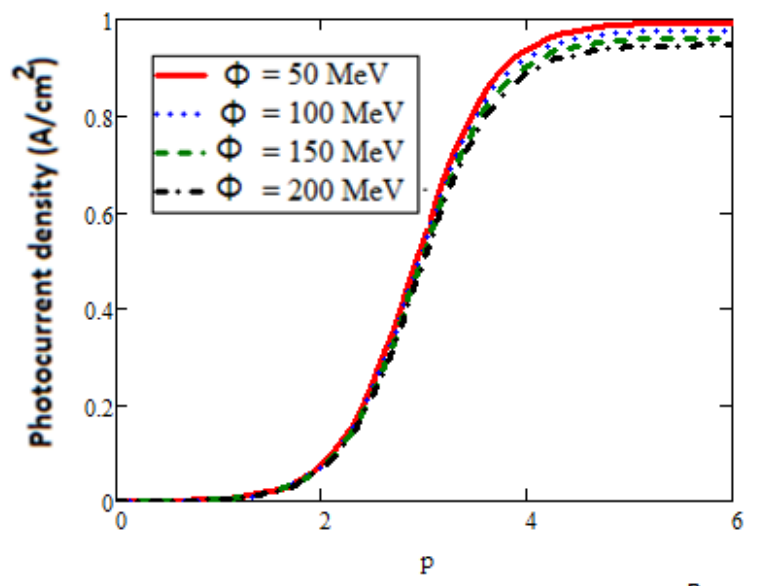

Junction recombinaison velocity $\left(p .10^{P} \mathrm{~cm} / \mathrm{s}\right)$

$3-\mathbf{a}) \mathbf{k l}=10 \mathrm{~cm} / \mathbf{s}^{2}$

Fig 3-a: Variation of the photocurrent density according to the recombination velocity at the junction

$\mathrm{Sf}\left(\mathrm{p} .10^{\mathrm{P}} \mathrm{cm} . \mathrm{s}^{-1}\right)$ for different values of irradiation energy $\lambda=0.7 \mu \mathrm{m} ; \mathrm{H}=0.03 \mathrm{~m} ; \mathrm{Z}=0,0001 \mathrm{~cm} ; \mathrm{L}_{0}=0,01 \mathrm{~cm}$ 


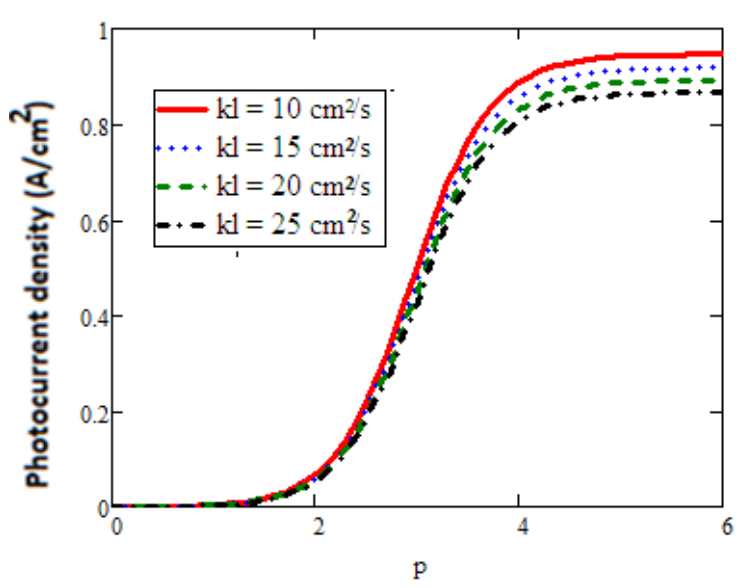

Junction recombinaison velocity $\left(p .10^{P} \mathrm{~cm} / \mathrm{s}\right)$

3-b) $\phi=50 \mathrm{Mev}$

Fig 3-b: Variation of the photocurrent density according to the recombination velocity at the junction

Sf $\left(\mathrm{p} \cdot 10^{\mathrm{P}} \mathrm{cm} \cdot \mathrm{s}^{-1}\right)$ for different values of the coefficient of damage

$\lambda=0.7 \mu \mathrm{m} ; \mathrm{H}=0,03 \mathrm{~m} ; \mathrm{Z}=0,0001 \mathrm{~cm} ; \mathrm{L}_{\mathrm{o}}=0,01 \mathrm{~cm}$

When Sf takes low values, the photocurrent density is quasi zero, reflecting the operation of the solar cell open circuit.

For large values of Sf, the photocurrent density takes an asymptotic value corresponding to the short-circuit current highlighting a massive crossing electrons at the junctions.

The short-circuit current decreases with the irradiation parameters because the density of electrons in the base decreases.

\subsection{Photovoltage Profile}

The photovoltage created by the accumulation of minority charge carriers at the junction, is obtained from the relationship of BOLTMANN (12):

$$
V=V_{T} \cdot \ln \left[1+\frac{N_{b}}{n_{0}^{2}} \cdot \delta(0, z, \lambda, k l, \phi, S f)\right]
$$

$\mathrm{V}_{\mathrm{T}}=\frac{K T}{e}$ thermal voltage

$\mathrm{Nb}$ : doping rate of acceptor atoms in the base

$\mathrm{n}_{0}$ : is the intrinsic carrier density at thermal equilibrium. thus:

$$
V_{P h}=\frac{K T}{q} \ln \left\{1+\frac{N_{b}}{n_{0}^{2}}\left[\frac{D \tanh \left(\frac{H}{2 L}\right)}{S_{f} L+D \tanh \left(\frac{H}{2 L}\right)}\right] \cdot \frac{L^{2}}{D} \cdot \alpha_{t}(1-R) \cdot F \cdot \exp \left(-\alpha_{t} \cdot z\right)\right\}
$$

Figures 04-a and 04-b show the profile of the photovoltage according to the recombination velocity at the junction Sf $\left(\mathrm{p} .10^{\mathrm{P}} \mathrm{cm} / \mathrm{s}\right)$ for different values of the irradiation energy and coefficient of damage.

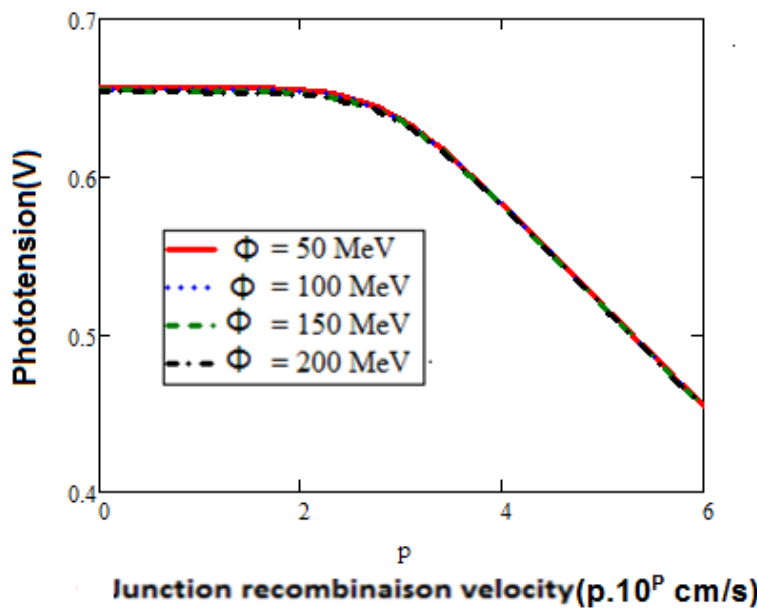

$4-a) k l=10 \mathrm{~cm} / \mathrm{s}^{2}$

Fig 4-a: Variation of the photovoltage according to the recombination velocity at the junction $\operatorname{Sf}\left(\mathrm{p} \cdot 10^{\mathrm{P}} \mathrm{cm} \cdot \mathrm{s}^{-1}\right)$ for different values of irradiation energy

$\lambda=0.7 \mu \mathrm{m} ; \mathrm{H}=0,03 \mathrm{~m} ; \mathrm{Z}=0,0001 \mathrm{~cm} ; \mathrm{L}_{\mathrm{o}}=0,01 \mathrm{~cm}$

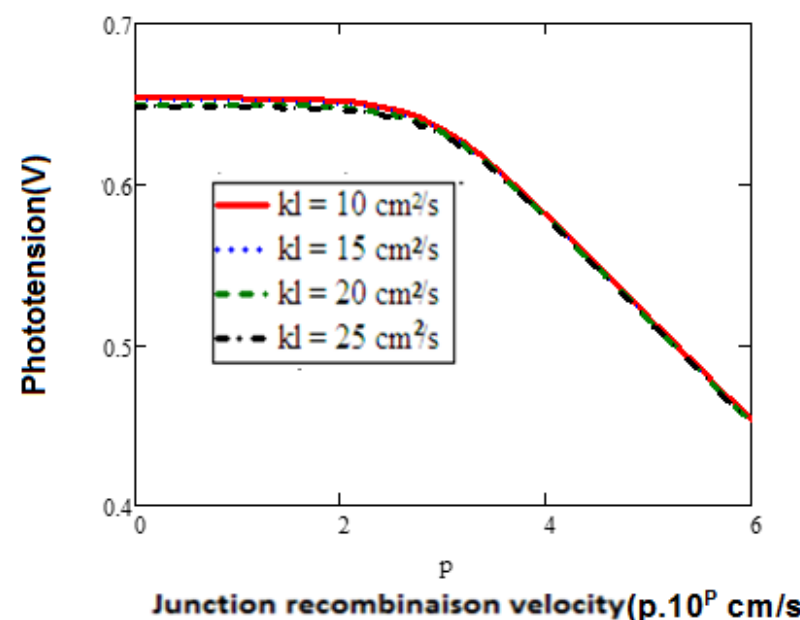

4-b) $\phi=50 \mathrm{Mev}$

Fig 4-b: Variation of the photovoltage according to the recombination velocity at the junction $\operatorname{Sf}\left(\mathrm{p} .10^{\mathrm{P}} \mathrm{cm} \cdot \mathrm{s}^{-1}\right)$ for different values of the coefficient of damage

$\lambda=0.7 \mu \mathrm{m} ; \mathrm{H}=0,03 \mathrm{~m} ; \mathrm{Z}=0,0001 \mathrm{~cm} ; \mathrm{L}_{\mathrm{o}}=0,01 \mathrm{~cm}$

For low values of $\mathrm{Sf}$, the photovoltage is constant and corresponds to the open circuit voltage.

The operation of the solar cell in the vicinity of open circuit resulting massive storage from charges on another side at the junctions.

The photovoltage open circuit decreases with the irradiation parameters because the electron density decreases as the irradiation energy or the coefficient of damage increases. 
Because of the increase in the recombination rate maintained by irradiation, the quantity of charges stored on the other side of the junction decreases leading to that of the photovoltage open circuit.

\subsection{Electrical Parameters of the Solar Cell}

\subsubsection{Characteristic V-I}

The 05-a and 05-b figures below show the profile of the photocurrent density according to the photovoltage which remains the same when the solar cell is under irradiation.

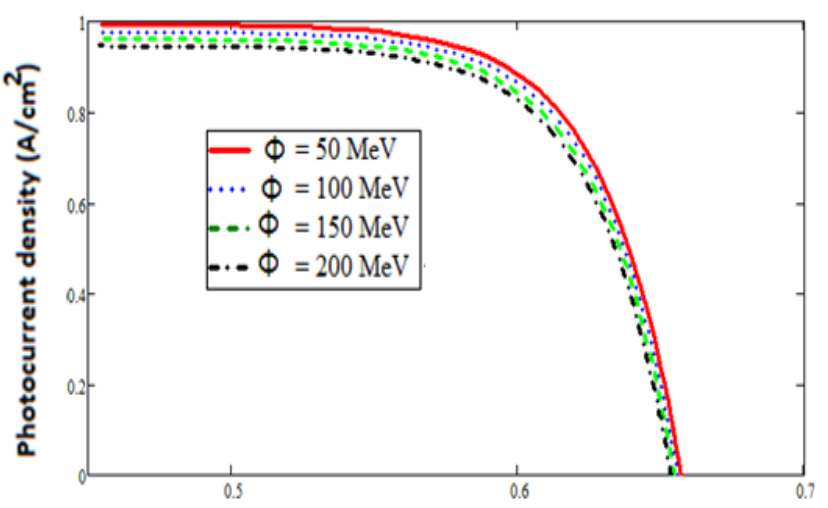

$5-\mathrm{a}) \mathrm{kl}=\mathbf{1 0} \mathrm{cm} / \mathrm{s}^{2}$

Fig 5-a: V-I characteristic of the solar cell

$\mathrm{Z}=0.0001 \mathrm{~cm} ; \mathrm{L}_{\mathrm{o}}=0,01 \mathrm{~cm} ; \mathrm{kl}=10 \mathrm{~cm}^{2} / \mathrm{s} ; \mathrm{H}=0.03 \mathrm{~cm}$ $\lambda=0.7 \mu \mathrm{m}$

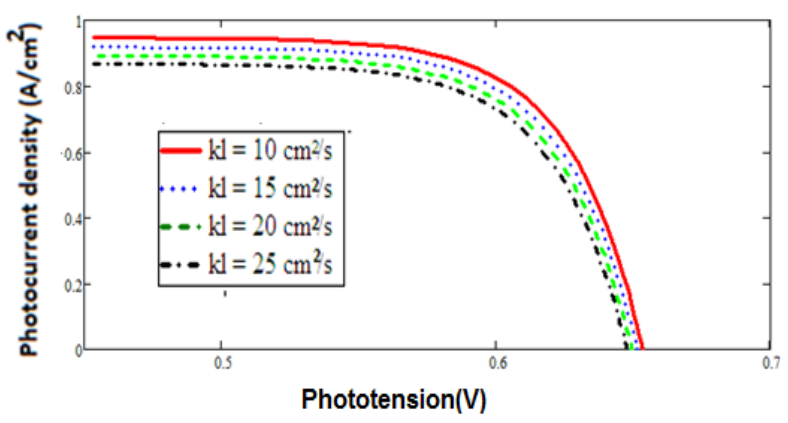

5-b) $\phi=50 \mathrm{Mev}$

Fig 5: V-I characteristic of the solar cell $(Z=0.0001 \mathrm{~cm}$; $\left.\mathrm{L}_{\mathrm{o}}=0,01 \mathrm{~cm} ; \phi=50 \mathrm{Mev} ; \mathrm{H}=0,03 \mathrm{~cm} \lambda=0,7 \mu \mathrm{m}\right)$

The analysis of the characteristic shows that the photovoltage is not independent from the photocurrent [4][5]

Sissoko added and deduced that the solar cell has two operating modes.

The solar cell behaves as a real voltage generator in the vicinity of the open circuit and as a real current generator in the vicinity of the short circuit.
For each mode of operation, an equivalent electrical circuit to the photocell is proposed.

\subsubsection{Shunt Resistance}

When the solar cell behaves like a real current generator, the equivalent electrical circuit to the solar cell is as follows: [6]-

[7]

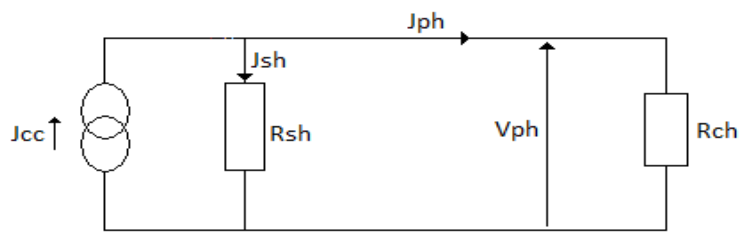

Fig 06: Equivalent circuit of the solar cell (current generator)

The study of this circuit, allows us to establish the expression of the shunt resistor: [5]-[8]

$$
R_{S H}\left(S_{f}, \lambda, k l, \phi, z\right)=\frac{V_{P H}\left(S_{f}, \lambda, k l, \phi, z\right)}{J_{C C}(\lambda, k l, \phi, z)-J_{P H}\left(S_{f}, \lambda, k l, \phi, z\right)}
$$

$\mathrm{J}_{\mathrm{cc}}$ represents the short -circuit photocurrent density.

Figures 07-a and 07-b show the shunt resistor the profile according to the recombination velocity at the junction Sf (p.10 $\mathrm{pm} \mathrm{s}^{-1}$ ) for respectively different values of the irradiation energy and the coefficient of damage.

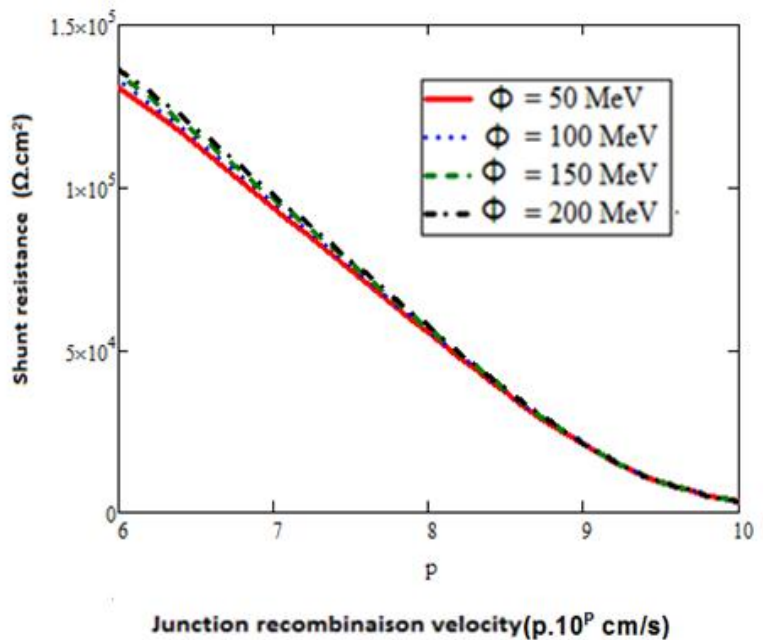

$7-\mathbf{a}) \mathbf{k l}=10 \mathrm{~cm} / \mathrm{s}^{2}$

Fig 7-a: Variation of the shunt resistance according to the recombination velocity at the junction for different values of the irradiation energy

$\lambda=0.7 \mu \mathrm{m} ; \mathrm{H}=0,03 \mathrm{~m} ; \mathrm{Z}=0,0001 \mathrm{~cm} ; \mathrm{L}_{\mathrm{o}}=0,01 \mathrm{~cm}$ 


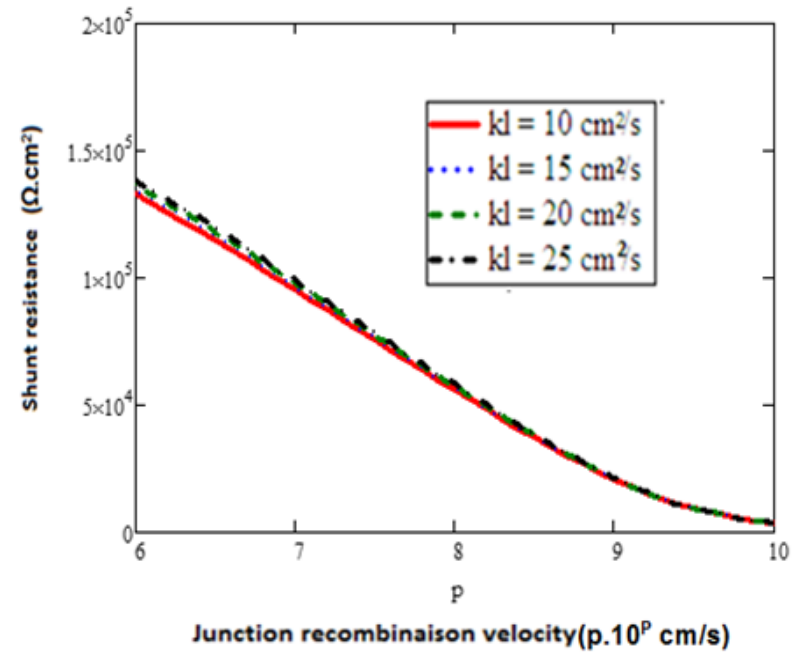

7-b) $\phi=50 \mathrm{Mev}$

Fig 7-b: Variation of the shunt resistance according to the recombination velocity at the junction for different values of the coefficient of damage

$\lambda=0.7 \mu \mathrm{m} ; \mathrm{H}=0.03 \mathrm{~m} ; \mathrm{Z}=0.0001 \mathrm{~cm} ; \mathrm{L}_{0}=0,01 \mathrm{~cm}$

The graphs show that the shunt resistance increases with irradiation parameters. Irradiation reduces leakage currents by increasing the recombination rate.

\subsubsection{Series Resistance}

The equivalent circuit model when the solar cell works like a real voltage generator is as follows: [6]-[7]

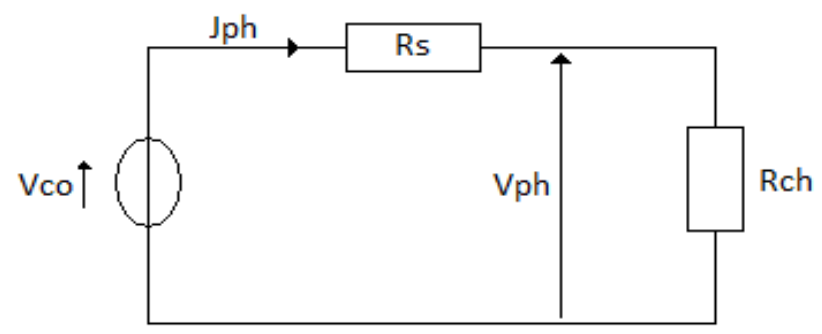

Fig 8: Equivalent circuit of the solar cell (voltage generator)

From the study of the electrical circuit, the resistance's expression is deduced: [5]-[8]

$R_{S}\left(S_{f}, \lambda, k l, \phi, z\right)=\frac{V_{C O}(\lambda, k l, \phi, z)-V_{P H}\left(S_{f}, \lambda, k l, \phi, z\right)}{J_{P H}\left(S_{f}, \lambda, k l, \phi, z\right)}$

Figures 09-a and 09-b show the profile of the series resistance according to the recombination velocity at the junction $\mathrm{Sf}\left(\mathrm{p} .10 \mathrm{p} \mathrm{cm} \mathrm{s}^{-1}\right)$ for respectively different values of the irradiation energy and the coefficient of damage.

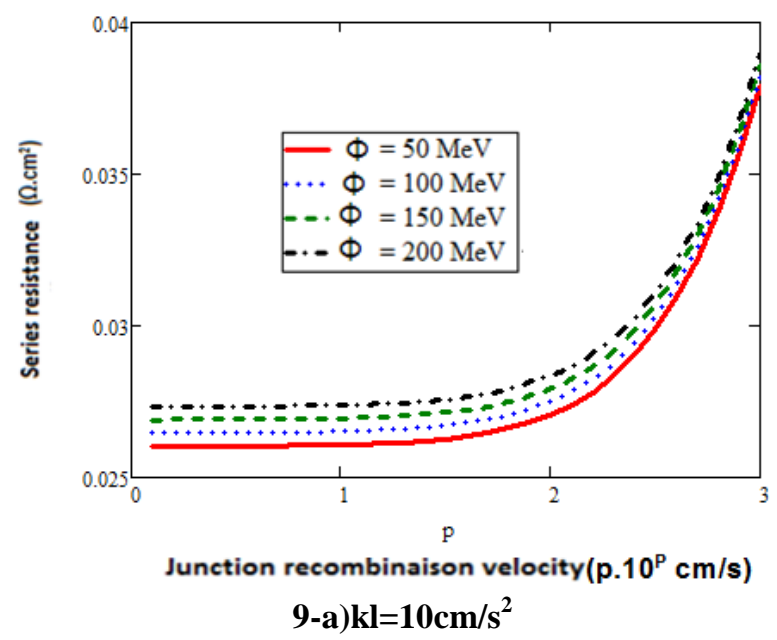

Fig 9-a: Variation of the series resistance according to the recombination velocity at the junction for different values of the irradiation energy

$\lambda=0.7 \mu \mathrm{m} ; \mathrm{H}=0,03 \mathrm{~m} ; \mathrm{Z}=0,0001 \mathrm{~cm} ; \mathrm{L}_{\mathrm{o}}=0,01 \mathrm{~cm}$

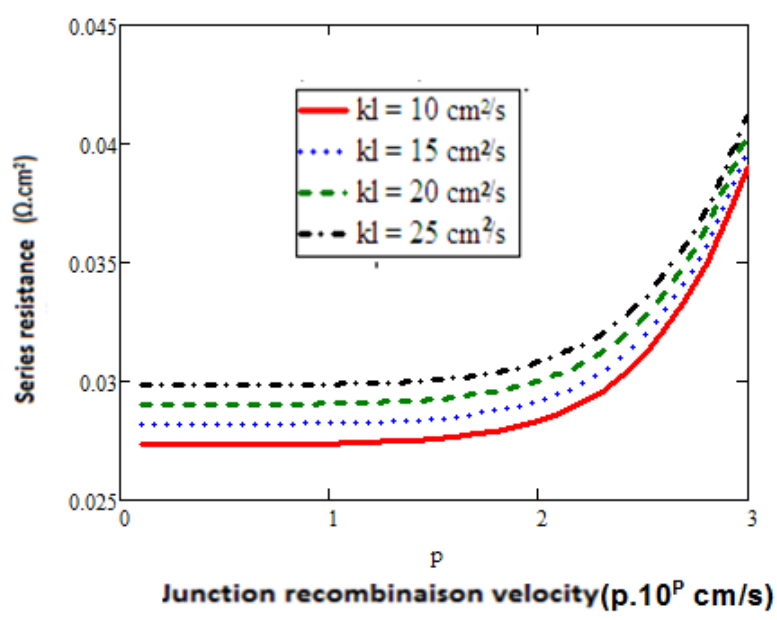

9-b) $\phi=50 \mathrm{Mev}$

Fig 9-b: Variation of the series resistance according to the recombination velocity at the junction for different values of the coefficient of damage

$\lambda=0.7 \mu \mathrm{m} ; \mathrm{H}=0,03 \mathrm{~m} ; \mathrm{Z}=0,0001 \mathrm{~cm} ; \mathrm{L}_{\mathrm{o}}=0,01 \mathrm{~cm}$

The graphs show that the irradiation did grow the series resistance. This means that irradiation increases the resistive effects of the material.

In the vicinity of the open circuit, the power supplied by the solar cell decreases when the irradiation increases.

\section{CONCLUSION}

The resolution of the equation of continuity has allowed us to establish the expression of minority carrier density of excess charge in the base of the solar cell.

From this density, the terms of the photocurrent density and photovoltage according to the wavelength has been 
deducted. From equivalent electrical models, expressions of series and shunt resistors have been established.

The influence of irradiation on the density of minority charge carriers in the base, the photocurrent density, photovoltage and series and shunt resistors, was studied.

The study has showed that irradiation was reducing the density of minority carriers, the photovoltage and photocurrent density because of rising recombination rate.

The shunt and series resistance increases with irradiation because leakage power reduces and the resistive effects of the base material of the solar cell increases.

\section{REFERENCES}

[1]. Kraner.H.W., radiation damage in silicon detectors, 2nde Pisa meeting on Advanced Detectors, Grosetto, Italy,June 3-7,1983

[2]. Bousse.L, Mostarshed.J., Hafeman.D, Jurtor.M., Adami.M and Nicolini.C, investigation of carrier transport through silicon wafers by photocurrent measurements, J.App.Phys.Vol 75(8), 1994,pp4000-4008.

[3]. H.L.Diallo,A.S.Maiga, A.Wareme and G.Sissoko, New approach of both junction and back surface recombination velocities in a 3D modelling study of a polychristallinesilicium solar cell,J.App.Phys.,Vol 42,2008,pp203-211

[4]. G.Sissoko , E.Nanema, A.Correa, P.M.Biteye, M.Adj, A.L.Ndiaye., silicon solar cell recombination parameters determination using the illuminated I-V characteristic, Renewable energy, vol 3, pp 18481851,Elsevier science Ltd, 1998.

[5]. M.L.Samb, M.Zoungrana, F.Toure,M.T.D.Diop, G.Sissoko., Etude en modélisation à 3-D d'une photopile au silicium en régime statiqueplacée dans un champ magnétique et sous éclairement multispectral, journal des sciences, Vol 10, $\mathrm{N}^{\circ} 4$,2010.pp :23-38

[6]. M.M.Dione, S.Mbodj, M.L.Samb,M.Dieng, M.Thiam, S.Ndoye, ,F.I.Barro,G.Sissoko., Vertical Junction Under constant Multispectral Light : Determination of Recombinaison Parameters, 24tth European photovoltaic solar energy conference and exhibition, 2009, Germany, pp : 465-469.

[7]. Mbodji. S., I. Ly, H.L. Diallo, M.M. Dione, O. Diasse and G. Sissoko. Modeling study of $n+/ p$ solar cell resistances from single I-V characteristic curve considering the junction recombination velocity (Sf). Res. J. Appl. Sci. Eng. Techn., 4(1), 2012, pp. 1-7.

[8]. F.I.Barro, S.Gaye,M.Deme, H.L.Diallo,M.LSamb,A.M.Samoura, S.Mbodj and G.Sissoko, Influence of grain boundary recombination velocity on the series and shunt resistances of a polycrystalline solar cell, Proceeding of the 23th European photovoltaic solar energy conference,2008, pp 612-615

[9]. M.A. Ould El Moujtaba, M. Ndiaye, A. Diao, M. Thiame, I.F. Barro and G. Sissoko, (2012). Théoretical study of the influence of irradiation on a silicon solar cell under multispectral illumination. Research Journal of
Applied Science, Engineering and Technology, 4(23), 50685073, ISSN : 2040-7467

[10]. Gaye.I ,M.A.O.EL MOUTJTABA, N.THIAM,I.TALL and G.SISSOKO.influence of irradiation and dammage coefficient on the minority density in the transient reponse for a bifacial silicon solar cell.Current Trends in technology science. ISSN :XXXX-XXXX.Volume XX,ISSUE :XXX.2012

[11]. A.Diao, M.Wade,M.Zoungrana ,M.Sarr ,M.Ndiaye,N.Thiam,A.Thiam ,A.Dieng , M.Ngom,A.S.Maiga,G.Sissoko,modèles

électriqueséquivalents en régime dynamiquefréquentiel de l'impédanced'une photopile bifaciale sous l'effet d'un champ magnétique constant pour un éclairementpolychromatique par la face arrière, journal des sciences, vol 11, $\mathrm{N}^{\circ} 1,2011$, pp : 20-26.

[12]. S.Mbodj, I.Ly, H.L.Diallo, M.M.Dione ,O.Diasse, G.Sissoko., Modeling study of N+/P Solar Cell Résistances from Single I-V characteristics curve considéring the Junction recombinaison velocity, Research Journal of Applied sciences, Maxwell scientific organization, 2012.4(1) pp :1-7

[13]. Diallo.H.L, B.Dieng, I.Ly, M.M.Dione ,M.Ndiaye ,O.H.Lemrabott ,Z.N.Bako, A.Wareme, G.Sissoko., Determination of the recombination and electrical parameters of a vertical multijunction silicon solar cell, Research Journal of Applied sciences, Maxwell scientific organization, 2012 , 4(16),pp :2626-2631

[14]. M.M.Dione, H.L.Diallo, M.Wade, I.Ly, M.Thiame, F.Toure, A.C.Gueye, N.Dieme, Z.N.Bako, S.Mbodj, F.IBarro, G.Sissoko. ,Determination of the shunt and series resistances of a vertical multijunction solar cell under constant multispectral light Proceedings of the 26th European Photovoltaic Solar Energy Conference (2011)1CV.6 .pp: :2 50 - 254

[15]. J.D.Arora, S.N.Singh, P.C.Mathur., surface recombinaison effects on the performance of $\mathrm{N}+\mathrm{p}$ step and diffused junction silicon solar cell,Solid state electronics,1981,24(8),pp : 739-749

[16]. Bouzidi, K.,M.chegaar and A. Bouhemadou, 2007.Solar cells parameters evaluation considering the series and shunt resistance.SolarEnerg.Mater.Solar cells,91:1647-1651

[17]. Bashahu, M.and A.Habyarimana,1995.Review and test of methods for determination of the solar cell series resistance.Renew Energy.6(2):127-138

[18]. R.J.Walters and G.P.Sammers.Space radiation effects in advanced solar cell materials and devices.Mat.Res.Soc.Symp.Proc.Vol.692

[19]. El-Adawi,M.K and I.A. Al-Nuaim,2002.A method to determine the solar cell series resistance from single I-V characteristic curve considering to shunt resistance.New approach. Vaccum,64: 33-36

[20]. G.Sissoko, G.Museruka, A.Correa,I.Gaye, A.L.Ndiaye.Light spectral effect on recombination parameters of silicon solar cell.World renewable energy congress, part III,pp 1487-1490,1996

[21]. Wise.J.F., 1970.Vertical junction hardered solar cell.U.S.Patent 3690853 